\title{
Elaboração do resumo documentário: qualidade, parâmetros e normas
}

\author{
Preparation of documentary abstract: quality, parameters and standards
}

\begin{abstract}
Vanda de Jesus Araújo
Graduada em Biblioteconomia pela Escola de Comunicações e Artes da Universidade de São Paulo - USP,

Brasil.

https://orcid.org/0000-0001-7243-6063

E-mail: vandajaraujo@yahoo.com.br

Cibele Araújo Camargo Marques dos Santos

Doutora em Ciência da Informação pela Escola de Comunicações e Artes da Universidade de São Paulo -USP,

Brasil.

Professora do Departamento de Informação e Cultura da Escola de Comunicações e Artes da Universidade de

São Paulo - ECA/USP, Brasil.

https://orcid.org/0000-0003-3782-3820

E-mail: cibeleac@usp.br
\end{abstract}

\section{Resumo}

Apresenta pesquisa teórica e prática do processo de elaboração de resumos, produtos documentários que permitem o desenvolvimento da produção e disseminação científica. Procura sumarizar parâmetros existentes, verificar a contribuição e aplicação destes na estruturação do resumo em artigos científicos, e refletir sobre a qualidade dos resumos apresentados. Tal investigação justifica-se pelo fato de o resumo ser elemento pré-textual estudado pelo campo da Organização e Representação do Conhecimento que possibilita a eficiência da recuperação da informação. Para tanto, foram selecionados e analisados resumos de uma amostra de trinta e cinco artigos científicos. Após a análise da amostra, observou-se que os parâmetros normativos mínimos identificados foram pouco aplicados na redação dos resumos, sendo omitidas uma ou mais das quatro partes consideradas essenciais num resumo: objetivo, metodologia, resultados e conclusões. Conclui que os parâmetros existentes são generalistas e pouco exigidos, dificultando a produção de resumos que atendam bem sua finalidade.

Palavras-chave: Resumos. Periódicos científicos. Organização e Representação do Conhecimento. Análise Documentária.

\begin{abstract}
Presents theoretical and practical research on the process of preparing abstracts, documentary products that allow the scientific production and dissemination development. It seeks to summarize existing parameters, verify their contribution and application in structuring the abstract in scientific articles, and reflect on the quality of the abstracts presented. Such investigation is justified by the fact that the abstract is a pre-textual element studied by the Knowledge Organization and Representation field, which enables the efficiency of information retrieval. To this end, abstracts from a sample of thirty-five scientific articles were selected and analyzed. After analyzing the sample, it was observed that the minimum normative parameters identified are little applied in the writing of abstracts, omitting one or more of the four parts considered essential in a summary: objective, methodology, results and conclusions. It concludes that the existing parameters are generalist and little required, making it difficult to produce abstracts that serve their purpose well.
\end{abstract}

Keywords: Abstracts. Scientific journals. Knowledge Organization. Documentary analysis. 


\section{Introdução}

A informação, qualquer que seja a definição atribuída, pouco adiantaria à formação do repertório do conhecimento humano se não pudesse ser transmitida e, uma vez transmitida, devidamente processada, realimentando, no processo da comunicação, o conhecimento.

No processo de transmissão da informação, foi possível chegar ao acúmulo de conhecimento devido ao armazenamento adequado e a uma recuperação eficiente que se tem ajustado continuamente para atender à necessidade de informação do homem.

O campo da Organização e Representação do Conhecimento compreende atividades relacionadas à descrição e à representação de conteúdo de documentos, cujos processos incluem a Análise Documentária, disciplina metodológica para análise de textos e seleção dos conteúdos a serem representados (LARA, 2011) que busca condensar a informação contida nos documentos para uma recuperação consistente.

A Análise Documentária consiste num aparato técnico e lógico para representação que proporciona o encontro do usuário da informação com seu objeto de busca e traduz-se em dois processos distintos, mas relacionados, a saber, a elaboração de resumos e a produção de índices, estes últimos podendo utilizar as linguagens documentárias.

No caso da elaboração de resumos, essa operação consiste na representação condensada do documento, a fim de facilitar a recuperação. Kobashi (1994, p. 68) considera que o texto de um documento original apresenta redundâncias, reiterações e repetições, estando, portanto, subjacente a ideia de que poderá ser sintetizado, sem a descaracterização da informação central.

O resumo documentário é o produto de uma operação de síntese que visa a recuperação da informação, pois evita a leitura integral de documento não pertinente à busca realizada. Em outras palavras, inserido em um sistema de informação, o resumo proporciona ao usuário uma busca eficaz, relevante e rápida, favorecendo a produção de conhecimento. Considerando que resumos têm a função de facilitar a circulação da informação, entende-se que algumas regras podem ser estabelecidas para manutenção das relações de sentido entre o documento original e sua representação, o resumo.

A atividade de resumir representa uma operação complexa, que deve ser apreendida, praticada e aperfeiçoada constantemente, de tal forma que esse produto documentário cumpra sua função social no contexto da produção e disseminação informacional. Sendo assim, este 
artigo é fruto de uma pesquisa sobre o tema, e faz um levantamento de publicações que versam sobre a importância da qualidade do resumo para a recuperação de documentos, à luz dos textos teóricos e das orientações e normativas para sua produção (ARAÚJO, 2019).

Complementarmente, pretendeu-se verificar o reflexo dos parâmetros vigentes e das exigências específicas dos publicadores na elaboração do resumo pelos autores de artigos científicos de Biblioteconomia e Ciência da Informação, o que consiste na parte prática deste estudo.

Este artigo apresenta pesquisa bibliográfica a respeito da produção do resumo, produto estudado pela Organização e Representação do Conhecimento com ênfase na Análise Documentária e no processo de condensação documentária devido à dependência que a eficácia da recuperação da informação tem desse processo. Lancaster, citando pesquisa de Lam-Adesina e Jones (2001 apud LANCASTER, 2004, p. 105) afirma, inclusive, que processos de recuperação automáticos baseados em resumos são mais eficazes que os baseados em textos integrais.

Ademais, a pesquisa bibliográfica, aliada à observação das normas e dos parâmetros de produção de resumo divulgados pelas editoras de periódicos, pode fornecer um panorama para análise da elaboração de resumos de um gênero textual específico, o artigo acadêmico, meio de comunicação largamente adotado na área científica.

\section{Métodos}

Primeiramente, realizou-se levantamento bibliográfico sobre a literatura que explica em que consiste o resumo documentário e que o classifica segundo critérios definidos. Identificouse nessa literatura recomendações para a elaboração desse tipo de representação.

A seguir, realizou-se a leitura de documentos das instituições normalizadoras como a Associação Brasileira de Normas Técnicas (ABNT), a International Standard Organization (ISO) e a National Information Standards Organization (NISO) dos Estados Unidos. Para complementar a literatura sobre elaboração de resumos, foram observadas as recomendações para autores, publicadas como condição para submissão de artigos por periódicos de uma amostra selecionada. A pesquisa nas páginas eletrônicas dessas revistas foi possibilitada pelo Portal de Busca Integrada da USP. 
Para atingir os objetivos práticos apontados, foi analisada uma amostra de artigos científicos com temática sobre estudos de indexação publicados no ano de 2017, coletados para um projeto anterior, selecionados da Base de Dados Referencial de Artigos de Periódicos em Ciência da Informação - BRAPCI. Essa seleção foi realizada pela busca em "Todos os campos" na base combinado com "2017" e "indexação", que resultaram em 35 artigos para a amostra, pertencentes a 20 títulos de revistas científicas da área numerados para identificação de 1 a 35 .

Os resumos de 1 a 35 foram então analisados em detalhe, com a identificação das partes do resumo. Procedeu-se então a uma sistematização dos resultados em tabelas, a fim de que algumas considerações pudessem ser depreendidas da análise. Este estudo teve, portanto, um caráter quantitativo e qualitativo.

Finalmente, foram apontadas questões surgidas durante a pesquisa, mas que, em favor do recorte temático, não puderam ser desenvolvidas, mas permitem lançar um olhar para o futuro dessa operação documentária na produção e disseminação do conhecimento.

\section{Resumos documentários, leitura, padrões de elaboração e normas}

Segundo Kobashi (1995, p. 47), o texto científico normalmente tem natureza argumentativa, elaborado com o intuito de expor metodicamente os resultados da observação de um fenômeno, donde vem a importância desse tipo de texto tanto para a difusão, quanto para a construção de novas informações científicas.

O resumo de um artigo pode ser a primeira e a única parte do documento lida pelo usuário quando ele busca artigos para sua pesquisa. Isso se deve ao fato de a busca, muitas vezes, recuperar centenas de documentos e o usuário, não dispondo de tempo para ler grande quantidade de artigos, vê-se obrigado a selecionar aquilo que lerá na íntegra, descartando o excedente. Tal seleção é viabilizada por um sistema de informação, que utiliza geralmente elementos pré-textuais, em especial o resumo, para representar o conteúdo do documental.

Kobashi (1994, p. 82-83) afirma que a função primordial do resumo é fornecer ao leitor o conteúdo informacional básico do texto, considerando dois tipos principais desse produto documentário: o resumo informativo e o resumo indicativo.

Como a elaboração de resumos envolve um conjunto de procedimentos documentários, de forma geral, divide-se esse processo em algumas etapas, de análise, síntese e representação. 
A análise consta da leitura do documento que se pretende resumir. Nessa etapa, as informações principais do documento devem ser percebidas. Ocorre então uma desestruturação do texto, a fim de que o resumidor faça a distinção entre informação essencial e informação acessória.

Na etapa da síntese, ocorre o inverso: as informações que foram consideradas essenciais são reestruturadas a fim de produzir um novo texto, expresso numa representação daquele documento, o resumo.

O resumo, a princípio, não é uma tarefa exclusivamente documentária. Profissionais de outras áreas, como jornalistas, lidam com a elaboração de resumos. Ademais o resumo é também um gênero escolar, entendido como conhecimento geral. É por isso que, nesta pesquisa, delimitou-se o resumo como o documentário, isto é, aquele definido como "representação concisa e acurada do conteúdo de um documento" (CUNHA, 2008, p. 323).

O resumo documentário é produzido pelo profissional resumidor segundo regras específicas para sua elaboração. Segundo Kobashi (1994, p. 1), ele deve guardar principalmente as relações de semelhança e contiguidade em relação ao texto original, em níveis distintos.

A regra de semelhança se relaciona à mensagem contida no texto. Assim, a informação essencial contida no texto-base deve ser preservada pelo documentalista no texto resumidor, que é um novo texto, podendo ser autônomo, se informativo, mas que continua relacionado à mensagem do texto-base.

A regra de contiguidade, por sua vez, indica que, no que concerne à organização textual, o resumo deve preservar a proximidade da estrutura do texto. Esse é também um modo de preservar a organização formal do texto original.

Ao estabelecer essas relações, a preocupação do documentalista consiste em manter a equivalência de sentido e forma entre o texto-base e o resumo que redige. Entretanto, essa ideia de um texto em si mesmo, apenas relacionado ao original, não é suficiente para garantir um resumo bem elaborado, até mesmo porque os mecanismos de elaboração não são claros: cada um compreende e seleciona conteúdo a seu modo.

Kobashi propõe então uma metodologia de elaboração de produtos documentários baseada em Van Dijk e Kintsh que se ancora no reconhecimento da superestrutura textual, esquemas mentais que seriam capazes de auxiliar na compreensão do sentido global de um texto 
(KOBASHI, 1994, p. 70). A vantagem da adoção dessa metodologia é que ela pode ser ensinada e transmitida.

A autora procura tornar essa superestrutura, que é abstrata, visível nos tipos textuais. No caso do artigo científico, existe ordenação que se exprime em certos tipos textuais argumentativos. Esses tipos são dotados das categorias tema, problema, hipótese, metodologia, resultados e conclusão.

Ainda pelo viés linguístico, uma forma de entender a questão é pensar na relação entre leitor, texto e discurso, como proposto por Alves, Neves e Fujita (2016). Seguindo esta abordagem, o texto deve ser entendido em sua totalidade que se refere não apenas à substância do texto em si, mas ao contexto e aos atores implicados em seu ciclo de produção e circulação. Ora, o contexto, no sentido discutido, só pode ser compreendido como dinâmico. Em termos de adequação ao contexto, um resumo só pode ser considerado adequado de modo relativo, segundo fatores como instituição, usuários e período.

Essa ideia vai ao encontro de Lancaster (2004) que ressalta a importância do contexto de produção e recepção. Além de descrever as características, o autor faz recomendações para serem consideradas na elaboração do resumo, bem como o que deve ser evitado, baseando-se em normas mais amplas. Entretanto ressalta que o resumidor deve obedecer a outras diretrizes mais específicas, como as instruções da instituição para a qual trabalha, finalidade do produto documentário e público a que pretende atender, fatores capazes de alterar significativamente a operação de resumir.

Para Fujita (2004, p. 4), a leitura documentária é uma atividade profissional, direcionada a um fim específico, mas nem por isso prescinde da regra de que existe uma intersecção entre leitor (com seu conhecimento prévio e estratégias), texto (com a intenção do autor, forma e conteúdo) e contexto (psicológico, social, físico).

Nesse cruzamento de variáveis, existe, portanto, uma complexidade capaz não apenas de construir novos conhecimentos, como também de causar ruídos e desinformações, resultantes da tensão leitor-texto-contexto. Ao transpor a forma de interpretar a leitura para o campo da leitura documentária, esse ruído na comunicação surge das dificuldades encontradas pelo resumidor em entender o conteúdo do documento, o qual, por sua vez, esconde o contexto do autor, que não escreveu seu texto para fins de resumo. 
Além disso, pode haver diferenças entre as informações que o leitor resumidor considerou relevantes e as que o autor considerou originalmente. Há ainda uma outra dimensão para se entender o processo de compreensão de textos e, por conseguinte, de síntese de conteúdo, envolvendo a cognição, que não se sobrepõe, mas complementa a dimensão linguística.

Para Cintra (1987, p. 32) a leitura compreensiva e fluida, de modo geral, se deve à internalização de esquemas mentais, responsáveis por antecipações e inferências que o leitor faz do texto. Porém, no caso da leitura documentária, estão implicadas estratégias cognitivas e metacognitivas que se relacionam a esses esquemas.

Frequentemente o profissional da informação não lê na íntegra o documento que está resumindo. Ele não conseguiria imprimir a velocidade necessária a seu trabalho se assim fosse. Devido ao conhecimento prévio que tem, que se esquematiza em estruturas mentais, é capaz de prever as sequências textuais e assim antecipar a localização da informação pertinente.

A qualidade do trabalho do resumidor pode impactar diretamente nas demais atividades de um sistema de informação. O profissional da informação, além de produzir resumos para auxiliar usuários em suas pesquisas, também os utiliza como meio para obtenção de outros produtos e serviços documentários, como é o caso da indexação: resumos são "muito úteis para o próprio profissional da informação, pois podem ajudá-lo no trabalho de identificar o assunto de um documento" (DIAS; NAVES, 2013, p. 16 apud OLIVEIRA, 2018, p. 250).

Mas esses dilemas costumam se limitar à redação profissional do resumo. Na prática, excetuando-se os artigos da área de Biblioteconomia e Ciência da informação, a maioria dos resumos não é produzida por um documentalista. O resumo de um artigo científico é, geralmente, produzido pelo próprio autor, como parte do processo de submissão de seu trabalho.

Sendo autor de seu próprio resumo, esse produtor de artigo pode não ter formação a respeito de um procedimento para resumir. Quanto a isso, Kobashi (1994, p. 128) salienta que: “O autor não é necessariamente o melhor resumidor de seu próprio texto". Uma pesquisa realizada por Diodato e Gandt (1991 apud LANCASTER, 2004, p. 90) concluiu que os autores apresentavam deficiências na redação de seus resumos.

As orientações dadas pelas revistas aos autores costumam indicar alguns parâmetros, como os apresentados por norma da ABNT. Entretanto eles são de caráter geral, insuficientes 
para nortearem sozinhos a produção de um resumo, ainda que compreendidos e aplicados de modo estrito.

Outro aspecto dessas orientações é que costumam priorizar detalhes de natureza formal, como, por exemplo, um espectro de elaboração de 150 a 250 palavras, ou a estruturação em parágrafo único. A ausência de precisão na orientação sobre a redação dos resumos costuma se traduzir em falta de padronização, que, mesmo quando redigidos dentro da formatação adequada, apresentam pouca objetividade nas camadas mais profundas do texto.

Todas as orientações existentes para a produção do resumo documentário visam à padronização desse tipo de texto a fim de facilitar a recuperação do texto-base dentro de um sistema de informação. Nesse sentido, um bom resumo poderia ser considerado aquele que permitisse a descoberta do documento apropriado no sistema para resposta a uma pesquisa.

Estendendo essa lógica ao usuário, quanto maior a satisfação dele diante da recuperação, maior qualidade teria o resumo. Mas seria mesmo possível mensurar a qualidade de um resumo pela recuperação final?

Lancaster fornece algumas pistas para pensar a respeito de qualidade do resumo. Um modo de entender essa qualidade seria observar em que medida o resumo atende à finalidade da instituição e aos usuários. Mas essa análise só poderia ser qualitativa ou poderia ser quantitativa também? O autor parte do princípio de que "indexação e resumo são atividades que não devem ser analisadas como um fim em si mesmas; são os resultados dessas atividades que devem ser avaliados e dentro de um contex to determinado" (LANCASTER, 2004, p. 135).

Apesar de apresentar exemplos, o autor reconhece as limitações implícitas nesses instrumentos que se relacionam à objetividade necessária para afirmações conclusivas sobre o tema. Um fator de incerteza é o usuário e suas demandas informacionais. Enquanto um certo grupo de usuários, por exemplo, pode avaliar uma recuperação como a contento, se forem substituídas essas pessoas, os resultados podem ser diferentes.

Além disso, os próprios resumidores realizam resumos de modo diferente do mesmo texto ao longo do tempo, o que pode gerar diferentes avaliações para um mesmo produto documentário, em que pese contribuir para tal diferença o fato de os resumos serem, em algumas situações, produzidos de modo intuitivo, sem considerar regras de elaboração. 
Outra dificuldade se impõe à mensuração da qualidade do resumo. Lancaster (2004, p. 123) diz que, embora as etapas de produção sejam as mesmas, a qualidade e a coerência são um pouco mais vagas quando se aplicam a resumos do que quando se aplicam à indexação.

A primeira etapa de elaboração de resumo consiste na análise conceitual. Segundo o autor, nessa etapa, pode-se avaliar o grau de coerência do resumo em relação às instruções da instituição para a qual o resumo foi redigido. Este procedimento foi aplicado na amostra analisada, pois as instruções das revistas serviram como ponderação na avaliação dos resumos publicados.

A segunda etapa da produção de resumo é chamada de tradução pelo autor. Nesse caso, seria possível medir a qualidade do resumo e não a coerência, porém, essa mensuração depende da subjetividade do usuário, ao considerar relevante ou não uma lista de documentos recuperados ou de resumos.

Apesar das pesquisas que Lancaster elencou, ele se viu obrigado a reconhecer que "o teste definitivo de um bom resumo consiste simplesmente em perguntar "será que ele permite ao leitor prever com exatidão se um item resumido é ou não relevante para seus interesses atuais?"' (LANCASTER, 2004, p 124). A dificuldade desse tipo de avaliação persiste, considerando-se variáveis mutáveis como leitores e a passagem do tempo.

O conhecimento do assunto do texto é um fator que aparece como favorável para a elaboração do resumo de qualidade. Lancaster (2004, p. 122) lembra um trabalho de Borko e Bernier que expõe que, quando alguém aprende a redigir resumos e é especialista num campo de conhecimento, redige os melhores resumos.

Lancaster (2004, p. 113), primando pela autossuficiência do texto resumidor, atribui três características a um bom resumo: brevidade, exatidão e clareza. Diz que quanto menor, melhor o resumo, desde que o sentido permaneça claro e não se sacrifique a exatidão. Tais características, porém, são mais princípios que diretrizes, ou seja, devem, sem dúvida, ser um horizonte para o resumidor, mas não representam o caminho concreto (passo-a-passo) para se obter o sucesso na tarefa de resumir.

Kobashi (1995, p. 36-37) ensina objetivamente a operação de resumir e indica os princípios para as informações documentárias cumprirem adequadamente suas funções, sem se ater à mensuração da qualidade. Para ela, esses princípios são máximas conversacionais de Greice. Assim, o resumo deve ter: concisão, pertinência, precisão e objetividade. 
A concisão consiste no fornecimento da informação suficiente; a pertinência, na representação fiel do conteúdo; a precisão, na eliminação de ambiguidades; a objetividade, na ausência de julgamento.

Volpato (2015, p. 226), oriundo da área das biológicas e, portanto, acostumado a escrever artigos com características de experimento, tem uma perspectiva diferente. Para ele, o resumo deve ser convidativo o suficiente para "levar o leitor do título para o trabalho completo". Por isso, recomenda não muito mais que 100 palavras para o resumo, pois um resumo menor é preferido pelo leitor.

Ao explicar sobre como fazer um resumo, o autor supracitado diz que "a função do resumo é expandir o conteúdo do título". É como se o resumo, que já é a síntese de um texto maior, estivesse sintetizado na frase do título. Assim, se olharmos para o percurso inverso, do mais sintético ao mais analítico, o corpo do texto do resumo seria, na verdade, uma análise do título.

Essa ideia de inversão, por assim dizer, vai ao encontro das orientações de Lancaster (2004, p. 113), quando recomenda fazer a estruturação do resumo a partir das informações contidas no título.

$\mathrm{Na}$ tentativa de tornar concretas as recomendações de produção de resumo, as associações e organizações que a parametrizam publicaram documentos com normas e recomendações para guiar sua elaboração. Mas nem mesmo profissionais da área, e este é o caso dos resumidores cuja produção foi analisada, encontram um norte preciso nessas diretrizes. Nos dias atuais, apesar de revisões realizadas nesses parâmetros, prevalece a afirmação de Kobashi (1995, p. 25) sobre a necessidade de metodologias que envolvam a síntese de conteúdo.

De acordo com a norma ISO 214:1976, norma revisada e confirmada como válida ainda em 2020, um resumo é definido como uma "representação abreviada e precisa do conteúdo de um documento, sem interpretação ou crítica adicional e sem distinção de quem escreveu o resumo" (INTERNATIONAL STANDARD ORGANIZATION, 1976, p. 1, tradução nossa). Desse modo, crítica e interpretação não seriam uma característica do resumo a princípio.

De acordo com a ISO, um resumo deve ser informativo ao ponto de trazer dados quantitativos e/ou qualitativos, no caso de textos que descrevem experimentos, enquanto resumos indicativos são mais adequados para artigos de revisão ou monografias. Assim, entende-se que a norma recomenda um tipo de resumo para cada tipo de texto. 
A American National Standards Institute (ANSI), representante dos EUA na ISO, através da norma Z39.14-1997 (R2015), fruto de atualizações feitas desde 1971, define um resumo bem elaborado como sendo "uma representação breve e objetiva do conteúdo de um documento principal ou uma apresentação oral" (NATIONAL INFORMATION STANDARDS ORGANIZATION, 1997, p. 1, tradução nossa).

Esse protocolo determina ainda a localização do resumo dentro do texto. No caso do artigo científico, diz: "Em uma revista, um resumo deve ser colocado na primeira página de cada item resumido entre o título e o início do texto", primando pela utilidade principal do resumo e valorizando o tempo do leitor.

Esta norma define os tipos de resumo de modo bem conciso. O resumo informativo é uma condensação do documento original, refletindo seu "tom e conteúdo", já o resumo indicativo trata de uma descrição que vai além da paráfrase do conteúdo do texto original. Sobre o resumo indicativo, a norma diz que pode não conter metodologia ou resultados, mas contém sempre objetivos (NATIONAL INFORMATION STANDARDS ORGANIZATION, 1997 p. 4). Lancaster (1994, p. 101) diz algo semelhante, que o resumo indicativo prescinde de resultados, conclusões e recomendações.

A norma Z39.14 reconhece que, embora não haja grande rigidez sobre para quais tipos de texto aplicar um tipo ou outro, o resumo informativo seria mais indicado para representar experimentos, investigações ou pesquisas (NATIONAL INFORMATION STANDARDS ORGANIZATION, 1997 p. 4). Por sua vez, o resumo indicativo seria mais adequado para editoriais, ensaios, opiniões, descrições, livros, anais de conferências, diretórios, bibliografias, listas e relatórios.

Os elementos essenciais do resumo são generalizados pela norma Z39.14 como quatro: objetivo, metodologia, resultados e conclusões. Conforme a definição presente nesta norma, a parte do objetivo abarca a anotação dos objetivos principais, o escopo do estudo e as razões pelas quais o documento foi produzido (NATIONAL INFORMATION STANDARDS ORGANIZATION, 1997, p. 4). Nessa definição ampla, o resumo pode incluir a contextualização e a justificativa.

A metodologia é considerada a parte que explica como o estudo foi desenvolvido. Nessa parte podem aparecer os procedimentos utilizados, o escopo teórico, as técnicas, as abordagens de pesquisa adotadas e até materiais utilizados se houver necessidade de ênfase. Por outro lado, 
sobre elementos de conteúdo, a Z39.14 ressalva que apenas o necessário para a compreensão da metodologia deve ser expresso no resumo (NATIONAL INFORMATION STANDARDS ORGANIZATION, 1997, p. 4).

A parte sobre os resultados deve ser escrita da forma mais concisa e objetiva possível, priorizando as informações que contradizem opiniões anteriores na literatura. Os resultados podem ser experimentais ou teóricos, podem conter dados coletados, relacionamentos, correlações e efeitos observados, entre outros.

A conclusão descreve a implicação dos resultados, relacionando-se com os objetivos do documento. Podem incluir recomendações, avaliações, solicitações, sugestões, novos relacionamentos e hipóteses aceitas ou rejeitadas.

Ademais, a norma ANSI/NISO Z39.14 reforça que na medida em que o resumo é lido na presença do título, o autor deve evitar o uso de declarações que se assemelham a versões textuais do título, principalmente na parte "objetivo" do resumo (NATIONAL INFORMATION STANDARDS ORGANIZATION, 1997, p. 4). Tal recomendação contrasta coma ideia de Volpato (2015) de "expansão do texto" no resumo.

No âmbito brasileiro, a Associação Brasileira de Normas Técnicas (ABNT), por meio da norma NBR 6028, estabelece regras para a produção de resumo, definindo-o como uma "apresentação concisa dos pontos relevantes de um documento" (ASSOCIAÇÃO BRASILEIRA DE NORMAS TÉCNICAS, 2003, p. 1).

A NBR 6028 informa que o resumo deve ressaltar: objetivos, métodos, resultados, conclusões, porém a ordem e extensão desses itens dependerão do tipo de resumo (informativo ou indicativo) e do tratamento de cada item no trabalho original (ASSOCIAÇÃO BRASILEIRA DE NORMAS TÉCNICAS, 2003, p. 2). Assim, essa declaração abre margem para considerar que um resumo indicativo poderia conter todas as quatro partes essenciais.

No sentido de relacionar as definições teóricas, os parâmetros estabelecidos pelas normas sobre resumo e questões práticas, são apresentados os resultados da análise de uma amostra de resumos da área de Organização e Representação do Conhecimento. 


\section{Resultados e discussões}

Quanto à aplicação dos parâmetros gerais (ABNT e ISO), as revistas científicas, cujos artigos fizeram parte da amostra, apresentaram as diretrizes para os autores com orientações relacionadas, em maior ou menor grau, às regras de produção de resumos. A maioria dessas diretrizes citam a ABNT, sem especificar que deve ser utilizada a NBR 6028.

Quanto à estrutura superficial, nessas diretrizes, os resumos devem ter entre 100 e 250 palavras na maioria das vezes. Nessa amostra de artigos, 9 resumos excedem pelo menos um dos parâmetros, isto é, a norma adotada ou a diretriz da própria revista. A extensão média dos resumos foi de 198,8 palavras.

Algumas orientações aos autores trazem recomendação mais extensa quanto às partes que o resumo deve conter. Indicam que o resumo deve constar de uma "sequência de frases concisas e objetivas", como é o caso das revistas do IBICT (INSTITUTO BRASILEIRO DE INFORMAÇÃO EM CIÊNCIA E TECNOLOGIA, 20--), podendo apresentar, por exemplo: problema, solução e conclusões; contextualização; lacuna; propósito. Preveem que a ordem desses elementos pode se alterar ou mesmo que alguns deles podem ser omitidos.

A partir da concepção teórica estabelecida foi considerado para a análise da amostra como um resumo completo aquele que contém objetivo, metodologia, resultados e conclusões. Essas 4 partes foram consideradas partes essenciais, pois estão de acordo com a ISO e ABNT representam o mínimo a se esperar de um resumo.

O resumo indicativo pode ter metodologia e resultados omitidos, ou até mesmo conclusões, segundo Lancaster (2004). Assim, sempre que um resumo carecer de alguma dessas partes, pode ser considerado resumo indicativo.

Outras partes que ocorrem no resumo informativo foram consideradas não essenciais por não figurarem explicitamente nos parâmetros mais utilizados. Porém, as partes introdução/contextualização foram recorrentes nos resumos analisados. Além disso, considerou-se a introdução/contextualização parte importante em um texto, seja ele resumo, notícia, monografia, ou outro gênero textual, sendo natural que todo texto, por representar um todo uno e coeso, tenha começo, meio e fim.

No âmbito deste artigo não é feita uma diferenciação entre introdução e contextualização, isto é, ambas foram contabilizadas como aquele elemento inicial, de 
apresentação de um texto. Entretanto, parece haver, na prática, certa diferença semântica no emprego de um ou de outro termo.

As diretrizes da revista Encontros Bibli, por exemplo, definem contextualização como "uma ou duas sentenças que identifique onde seu trabalho está inserido dentro da grande área" (ENCONTROS BIBLI, 20--). Nesse caso, contextualização seria um período sintático que retoma de modo mais geral o histórico da grande área, sem a particularização do tema do artigo.

Desta forma, pode ser depreendido que a introdução, é a explicitação do trabalho em área específica? Essa resposta não foi encontrada nos autores estudados, mas é possível identificar esta diferença nos artigos analisados, que trazem um ou outro elemento, às vezes, os dois. No trecho a seguir, retirado do resumo do Artigo 9 percebe-se a diferença entre contextualização e introdução.

Um sistema de recuperação de informação é um elemento mediador entre um estoque de informação e seus usuários. Sua eficácia depende do controle adequado da linguagem de representação dos itens de informações e das buscas de seus usuários. Este trabalho apresenta um modelo de recuperação de informação baseada em ontologia que usa a estrutura formal do modelo espaço vetorial.

Fonte: Perspectivas em Ciência da Informação, v. 22, n. 2, 2017 p. 170.

Nos períodos iniciais, faz-se uma contextualização, discorrendo sobre a recuperação da informação de forma generalista. A partir do terceiro período é que se faz uma introdução sobre a contribuição daquele artigo em particular, a "apresentação de um modelo de recuperação da informação baseado em ontologia”.

Como o embasamento teórico para caracterizar a nuance entre introdução e contextualização não foi esclarecido na pesquisa bibliográfica realizada, optou-se por nomear a parte de apresentação do resumo de contextualização, por ser de significado mais amplo.

Em certos resumos, é mais difícil perceber a diferença entre objetivo e contextualização. Isso porque um resumo pode já iniciar com palavra que indique propósito, como é o caso do verbo "buscar", como no exemplo retirado do resumo do Artigo 7: "Busca investigar as bases intelectuais dos bolsistas de produtividade em pesquisa [...]”. É considerado, neste artigo, que a presença de uma palavra ou expressão que indique propósito basta para o enquadramento do início do período como objetivo e não como contextualização. Assim, o resumo desse artigo tem objetivo, mas não contextualização.

Há posições que justificam essa opção, como é o caso do IMRD, estruturação utilizada desde 1940 (SOLLACI; PEREIRA, 2004, p. 364), que compreende introdução (I), métodos 
(M), resultados (R) e discussão (D). Nesse formato, não há segmentação do texto do resumo em objetivo, sendo possível depreender que o objetivo está incluído na introdução, como aconteceu em 5 dos 35 artigos analisados.

Há autores que defendem que se inicie o resumo já pelo objetivo. Volpato (2016, p. 53) diz: "Vá direto ao ponto (objetivo). Só inclua alguma justificativa se o entendimento do objeto requerer e se isso ampliar o número de leitores que entenderão esse objeto". Sem dúvida, ao iniciar com o objetivo, há economia de palavras, o que favorece o princípio de concisão.

Por outro lado, se não há palavra que indique objetivo, considera-se que há contextualização e não objetivo. É o caso do resumo do Artigo 8, que se inicia deste modo: "Analisa a indexação automática por sintagmas nominais de documentos [...]". Nesse caso, o verbo "analisar", conjugado na terceira pessoa do singular no modo indicativo, não é capaz de indicar per si um objetivo, sendo então considerado integrante da contextualização.

Para ilustrar essa questão, o resumo do Artigo 31 parece sintetizar bem a diferença entre contextualização e objetivo que pode ser estabelecida pela semântica das palavras, geralmente verbos, e expressões empregadas pelo autor. No trecho que inicia o texto: "Estuda aspectos relativos à representação temática da informação no contexto dos Repositórios Digitais. Objetiva analisar a representação da informação em tais ambientes", fica clara a diferença das partes pela semântica dos verbos empregados na contextualização ("estuda") e objetivo (“objetiva"), embora estejam no mesmo modo e pessoa verbal e em frases paralelas do ponto de vista sintático.

A classificação das partes do resumo na análise obedeceu a essa diferenciação estrita, apesar da norma Z39.14 abrir a possibilidade de ampliação sobre o conceito de objetivo, que acaba por englobar também a contextualização, como já comentado.

Finalmente, foi seguida a regra de que um mesmo período ou sequência de períodos não devem ser classificados mais de uma vez, isto é, um trecho de resumo considerado contextualização não pode ser, ao mesmo tempo, considerado objetivo.

Como descrito, foram utilizados 35 artigos na pesquisa, com indicação no Quadro 1, que especifica os artigos e as revistas a que pertencem e a análise das partes identificadas no resumo de cada artigo.

A partir dos dados apresentados, observa-se que, dos 35 resumos analisados, 13 continham todas as partes essenciais: objetivo, metodologia, resultados e conclusões. 
Quadro 1 - Artigos, revistas e partes do resumo identificadas

\begin{tabular}{|c|c|c|c|c|c|c|c|}
\hline Revista & Artigo & Contextualização & Objetivos & Justificativa & Metodologia & Resultados & Conclusão \\
\hline$A C B$ & 24 & & $x$ & & $\mathrm{x}$ & $x$ & \\
\hline Bibl. Esc em Rev. & 2 & $x$ & & & $x$ & & \\
\hline \multirow[t]{2}{*}{ BRAJIS } & 25 & $x$ & $\mathrm{x}$ & & & & $x$ \\
\hline & 34 & $\mathrm{x}$ & $\mathrm{x}$ & & $\mathrm{x}$ & & \\
\hline Ci. Inf. & 33 & $x$ & $x$ & & $\mathrm{x}$ & $x$ & $x$ \\
\hline \multirow[t]{2}{*}{ Ci. Inf. Rev } & 23 & $x$ & & & $x$ & $x$ & $x$ \\
\hline & 30 & $x$ & $\mathrm{x}$ & & $\mathrm{x}$ & $x$ & $x$ \\
\hline \multirow[t]{2}{*}{ Conhec. Ação } & 21 & $x$ & $\mathrm{x}$ & $\mathrm{x}$ & $\mathrm{x}$ & & \\
\hline & 27 & $x$ & $\mathrm{x}$ & & $\mathrm{x}$ & $x$ & $\mathrm{x}$ \\
\hline \multirow[t]{4}{*}{ Em Questão } & 7 & & $\mathrm{x}$ & & $x$ & $x$ & \\
\hline & 11 & $x$ & $x$ & & $\mathrm{x}$ & $\mathrm{x}$ & \\
\hline & 15 & $x$ & $x$ & $x$ & $x$ & & $x$ \\
\hline & 19 & $x$ & $x$ & & $x$ & $x$ & \\
\hline Encontros Bibli & 8 & $x$ & $\mathrm{x}$ & & $\mathrm{x}$ & $x$ & $x$ \\
\hline Folha de rosto & 22 & & $x$ & $x$ & $x$ & & $x$ \\
\hline \multirow[t]{4}{*}{ Inf. Inf. } & 5 & $x$ & $x$ & & $x$ & $x$ & $x$ \\
\hline & 10 & $x$ & $\mathrm{x}$ & & $\mathrm{x}$ & $x$ & $x$ \\
\hline & 13 & $x$ & $x$ & & $x$ & $x$ & $x$ \\
\hline & 26 & $x$ & $x$ & & $x$ & $x$ & $x$ \\
\hline Inf. Prof. & 3 & $x$ & $\mathrm{x}$ & & $x$ & $x$ & $x$ \\
\hline Inf. Soc. Contemp & 31 & $x$ & $x$ & & $x$ & $x$ & $\mathrm{x}$ \\
\hline IRIS & 20 & $x$ & $\mathrm{x}$ & & $x$ & & \\
\hline Perspectivas & 9 & $x$ & & & $\mathrm{x}$ & $x$ & \\
\hline Ponto de Acesso & 1 & $x$ & $x$ & & & & \\
\hline RaCin & 17 & $x$ & $\mathrm{x}$ & & $\mathrm{x}$ & $x$ & $x$ \\
\hline \multirow[t]{7}{*}{ RBBD } & 4 & $x$ & $\mathrm{x}$ & & & & \\
\hline & 6 & $x$ & $\mathrm{x}$ & & $x$ & & $x$ \\
\hline & 12 & $x$ & $x$ & & $x$ & & $x$ \\
\hline & 14 & $x$ & & & $x$ & & $x$ \\
\hline & 16 & $x$ & $x$ & & $x$ & $x$ & $x$ \\
\hline & 18 & $\mathrm{x}$ & $\mathrm{x}$ & & $\mathrm{x}$ & $\mathrm{x}$ & $\mathrm{x}$ \\
\hline & 32 & $x$ & & & $x$ & $x$ & $x$ \\
\hline $\mathrm{RDBCl}$ & 35 & $x$ & $x$ & & $\mathrm{x}$ & & \\
\hline REBECIN & 29 & $x$ & $x$ & & $x$ & $x$ & \\
\hline Transinformação & 28 & $\mathrm{x}$ & $\mathrm{x}$ & & $\mathrm{x}$ & & \\
\hline
\end{tabular}

Fonte: elaborado pelas autoras

A contextualização está presente em 32 dos artigos analisados. Esse dado reforça a contextualização como parte essencial no resumo, tanto quanto objetivo, metodologia, resultados e conclusões. O motivo pelo qual essa parte frequente não seja considerada essencial pelos parâmetros gerais de elaboração talvez seja o fato de se encontrar implícita na descrição de objetivo.

Quanto ao objetivo dos artigos, como 5 resumos não o apresentavam, foi possível concluir que esse é um elemento muito frequente. A NBR 6022, normalizadora da produção periódica considera a parte introdutória do artigo como um elemento textual obrigatório (ASSOCIAÇÃO BRASILEIRA DE NORMAS TÉCNICAS, 2018, p. 5). Naturalmente, na síntese do artigo, ou seja, no resumo, o referido elemento deve figurar, ainda que com menor extensão. 
A parte de justificativa não é elemento considerado essencial num resumo. Isso se refletiu na amostra analisada, em que apenas 3 artigos continham uma frase que justificasse os trabalhos relatados nos resumos.

A metodologia foi omitida em apenas 2 artigos. Esse foi, portanto, o elemento mais presente nos resumos da amostra. A ocorrência da metodologia nos resumos é positiva, na medida em que a inclusão dos métodos nos artigos, segundo Volpato (2015), informa sobre o planejamento e execução da pesquisa, permitindo que outros cientistas entendam a metodologia para analisar os resultados e conclusões, ou refazer o estudo, disponibilizando a forma de obtenção da base empírica da pesquisa.

Não se pode esquecer, porém, que a ausência de resultados e/ou conclusões pode significar escrita de um resumo indicativo. Mas isso é mera hipótese, pois, como poderá ser observado no Quadro 2, apenas uma revista entre as pertencentes à amostra indicou preferência por resumo indicativo. Quanto às recomendações, esse quadro sumariza quais delas: a) citam a ABNT, mesmo que modo geral, sem vincular ao resumo, b) recomendam explicitamente a aplicação na NBR 6028, c) solicitam resumo informativo ou resumo indicativo ou resumo estruturado e d) fornecem template para elaboração do artigo e do resumo.

Quadro 2: Elementos mencionados nas orientações das revistas.

\begin{tabular}{|c|c|c|c|c|c|c|}
\hline Revista & ABNT & NBR6028 & Informativo & Indicativo & Estruturado & Template \\
\hline ACB & $x$ & $x$ & $x$ & & & \\
\hline Bibl. Esc. Em R. & $x$ & $x$ & $x$ & & & \\
\hline BRAJIS & & & & $x$ & & $x$ \\
\hline Ci. Inf. & $x$ & & & & & \\
\hline Ci. Inf. Rev & $x$ & $x$ & & & & \\
\hline Conhecimento em ação & $x$ & $x$ & & & & \\
\hline Em Questão & $x$ & $x$ & & & & $x$ \\
\hline Encontros Bibli & $x$ & & & & $x$ & $x$ \\
\hline Folha de rosto & $x$ & $x$ & & & & \\
\hline Inf. Inf. & $x$ & & & & $x$ & $x$ \\
\hline Inf. na Soc. Contemp. & $x$ & $x$ & $\mathrm{x}$ & & & \\
\hline Inf. Prof. & $x$ & & & & $x$ & $x$ \\
\hline IRIS & $x$ & $\mathrm{x}$ & & & & $x$ \\
\hline Perspectivas & $x$ & & & & & \\
\hline Ponto de Acesso & $x$ & $\mathrm{x}$ & & & & \\
\hline RACin & $x$ & & & & & \\
\hline RBBD & $x$ & & $x$ & & & \\
\hline $\mathrm{RDBCl}$ & $\mathrm{x}$ & $\mathrm{x}$ & & & & $\mathrm{x}$ \\
\hline REBECIN & $x$ & $x$ & & & & \\
\hline Transinformação & $x$ & & & & & \\
\hline
\end{tabular}

Fonte: elaborado pelas autoras.

Como pode ser visto, apenas uma revista desta amostra não menciona a ABNT ao menos como regra geral de submissão. Uma possiblidade possível é a característica internacional da 
revista, especificamente mais ancorada no idioma inglês. De fato, a revista menciona a ISO, embora de modo genérico, sem vinculá-la ao resumo.

Já no que se refere à norma NBR 6028 da ABNT específica para resumo, 11 revistas entre 20 citam-na expressamente. Este número de menções a norma, no entanto, pode ser explicado pela indicação de uso que a NBR 6022 já faz à NBR 6028 (ASSOCIAÇÃO BRASILEIRA DE NORMAS TÉCNICAS, 2018, p. 5).

Poucas revistas (5) especificaram o tipo de resumo que deveria ser feito. Essa informação é importante, pois dependendo do resumo que se espera é que o autor poderá preparar melhor seu texto.

Apenas 3 revistas solicitam resumo estruturado. Todos os artigos dessas revistas eram providos de resumos estruturados, exceto o resumo do Artigo 8, mas continha todas as partes essenciais. Por outro lado, não houve, na amostra, resumos estruturados sem a exigência expressa da revista.

A norma ANSI/NISO Z39.14 recomenda que se evitem começar o resumo de artigo nomeando o tipo de documento (NATIONAL INFORMATION STANDARDS ORGANIZATION, 1997, p. 6). Lancaster (2004, p. 113), por seu turno, não menciona o lugar do texto em que isso não deve ser feito, se no começo ou no meio do resumo, mas concorda com a norma. Embora a NBR 6028, que é mais citada nos artigos analisados, não se posicione a respeito, essa característica foi observada nos resumos analisados.

Muitos resumos mencionaram o tipo de documento que representavam, seja no início, seja no meio do texto. A exceção coube a 8 artigos. Essa característica já era esperada, pois não é criticada pela norma brasileira. Mas, se por um lado, escrever o tipo de documento pode comprometer o princípio da concisão, por outro lado, em certas construções frasais, é até mesmo um elemento de coesão referencial, que, se suprimido, poderia tornar a mensagem obscura ou até mesmo mais extensa. No exemplo do resumo do Artigo 24:

Esta pesquisa teve como objetivo mapear os periódicos da Universidade do Estado de Santa Catarina (UDESC), coletando dados, delineando suas características técnicas, buscando seus históricos, destacando a importância dos periódicos para as universidades. A pesquisa caracteriza-se como exploratória e faz uma abordagem qualiquantitativa. Foram identificadas 19 revistas publicadas pela UDESC, das quais uma não atendeu aos parâmetros da pesquisa.

Fonte: Revista ACB, v. 22, n. 2, esp., p. 343-358, 2017. 
Como se pode observar, o autor menciona o tipo de texto (pesquisa) em dois momentos. No início do resumo, facilmente essa informação acessória poderia ter sido retirada. Porém, na segunda ocorrência, a palavra "pesquisa" como que retoma os conceitos "coleta de dados", "delineamento das características técnicas" e "busca de históricos", que constituiriam um sintagma bem mais extenso que a palavra "pesquisa". Assim, no primeiro caso, deveria haver supressão, porém, no segundo, não há comprometimento da concisão, mas a prática dela.

Todos os resumos, incluindo os estruturados, encontravam-se em parágrafo único. Essa regra foi a única cumprida unanimemente, talvez até mesmo por intervenção dos editores.

Todas as revistas que tiveram resumos de artigos analisados fornecem diretrizes para autores, disponibilizadas em plataformas de layouts muito semelhantes. Isso se deve ao Sistema Eletrônico de Editoração de Revistas (SEER), um software desenvolvido para a construção e gestão de publicação periódica eletrônica (INSTITUTO BRASILEIRO DE INFORMAÇÃO EM CIÊNCIA E TECNOLOGIA, 2019), que serve de plataforma a grande número revistas de acesso aberto. Desse modo, tanto o mapa do site, quanto as diretrizes, seguem mais ou menos o mesmo padrão.

\section{Considerações finais}

As recomendações das revistas da amostra analisada em relação às diretrizes para elaboração de resumos podem ser consideradas gerais. A maior parte delas reproduz parte da norma brasileira ou sugere o uso da norma para artigos, sem dar maiores detalhes de produção do resumo.

Devido ao fato da amostra e do recorte da pesquisa serem restritos, não ficou claro, pela análise, o quanto as orientações disponibilizadas aos autores pelas revistas encaminharam a produção de resumos para o atendimento da configuração esperada para um artigo científico, sendo possível, no entanto observar que permitiram o preenchimento dos requisitos mínimos das normas e das orientações oferecidas.

Por outro lado, pôde-se verificar que, embora poucas, algumas orientações comprovadamente impactaram a elaboração do resumo. $\mathrm{O}$ fato mais contundente dessa afirmação é o resumo estruturado. Como esse tipo de resumo exige a "marcação gráfica" de cada parte do resumo, os autores cumpriram com os requisitos solicitados. Assim, a estruturação 
do resumo parece colaborar com a elaboração, haja vista que os resumos das três revistas que exigiam estruturação continham todas as partes consideradas essenciais.

Devido a rigidez formal, os resumos estruturados podem ser úteis num contexto em que a recuperação da informação se torna cada vez mais informatizada. Hartley et al. (1996 apud LANCASTER, 2004, p. 105), descobriram que esses resumos são mais eficazes na hora da busca por exemplo.

Considerou-se um ponto positivo a disponibilização de templates aos autores, por ser uma forma de orientação à redação do artigo a partir de um modelo que atende normas vigentes para apresentação, citação, referências e redação do resumo, sendo que 7 revistas da amostra fizeram esta solicitação. Porém, os reflexos mais positivos na elaboração dos resumos ocorrem quando as revistas exigiram o resumo estruturado, fazendo com que os resumos fossem elaborados com todas as partes essenciais, o que não ocorreu necessariamente com os resumos que foram feitos com base nos templates dos artigos.

As diretrizes e normas para elaboração de resumos, apesar das lacunas apresentadas, poderiam ser mais respeitadas, pois orientam a escrita de um resumo a contento, isto é, adequado a sua finalidade. Para tanto, as revistas publicadoras poderiam fortalecer a exigência dos parâmetros no momento da submissão de artigos.

Em relação a Análise Documentária, enquanto disciplina metodológica, cabe a esta pesquisa e o estudo do tratamento da informação presente nos textos dos documentos. $\mathrm{O}$ panorama apresentado neste artigo, referente à elaboração do resumo, produto que concretiza o conhecimento de tal disciplina na vida social, aponta para a necessidade de maior sistematização dos procedimentos para a representação e condensação de conteúdo. Além disso, mostra dificuldades para as quais novos instrumentos possam que ser criados.

As descobertas mencionadas nesta pesquisa mostram a importância da redação do resumo no processo da escrita científica na Ciência da Informação e nas outras áreas do conhecimento, e que esta pode aprimorada na medida em que é utilizada para a disseminação do conhecimento. Nesse sentido, o preparo do autor no meio acadêmico é fundamental para a escrita de resumos e, por extensão, de artigos científicos de qualidade: não basta pesquisar e obter o conhecimento; é preciso saber transmitir, cabendo à universidade a tarefa de ensinar como fazer essa transmissão, que pode ser realizada, em relação à elaboração de resumos, a partir do aparato metodológico fornecido pela Análise Documentária. 


\section{Referências}

ALVES, Roberta Caroline Vesu; NEVES, Dulce Amélia de Brito; FUJITA, Mariângela Spotti Lopes. Estratégias metacognitivas para análise de assunto: aspectos teóricos de superestrutura e esquemas sobre textos literários infanto-juvenis. Informação \& Sociedade: Estudos, João Pessoa, v. 26, n. 1, p.7-19, jan./abr.2016. Disponível em: http://hdl.handle.net/20.500.11959/brapci/92843. Acesso em: 02 nov. 2019.

ARAUJO, Vanda de Jesus. Elaboração do resumo documentário: qualidade, parâmetros e normas. 2019. TCC (Graduação em Biblioteconomia) - Escola de Comunicações e Artes, Universidade de São Paulo, São Paulo, 2019.

ASSOCIAÇÃO BRASILEIRA DE NORMAS TÉCNICAS. ABNT NBR 6028: informação e documentação: resumo: apresentação. Rio de Janeiro: ABNT, 2003.

ASSOCIAÇÃO BRASILEIRA DE NORMAS TÉCNICAS. ABNT NBR 6022: artigo em publicação periódica científica impressa: apresentação. Rio de Janeiro: ABNT, nov. 2018.

CINTRA, Ana Maria Marques. Estratégias de leitura em documentação. In: SMIT, Johanna Wilhelmina (org.). Análise documentária: a análise da síntese. 2. ed. Brasília: SCT; CNPq; IBICT, 1987. p. 27-36.

CUNHA, Murilo Bastos da. Dicionário de Biblioteconomia e Arquivologia. Brasília: Briquet de Lemos, 2008.

ENCONTROS BIBLI. Submissões. Florianópolis: UFSC, [20--] Disponível em: https://periodicos.ufsc.br/index.php/eb/about/submissions. Acesso em 26 out. 2019.

FUJITA, Mariângela Spotti Lopes. A leitura documentária na perspectiva de suas variáveis: leitor-texto-contexto. Datagramazero, João Pessoa, v. 5, n. 4, p. 1-23, 2004. Disponível em: http://www.brapci.inf.br/index.php/article/view/0000007547/f439490af520c6a64bbdd99c4a7 4f163/. Acesso em: 10 nov. 2019.

INSTITUTO BRASILEIRO DE INFORMAÇÃO EM CIÊNCIA E TECNOLOGIA. Sistema Eletrônico de Editoração de Revistas (SEER). Rio de Janeiro, IBICT, [20--]. Disponível em: http://www.ibict.br/tecnologias-para-informacao/seer. Acesso em 03 nov. 2019.

INTERNATIONAL STANDARD ORGANIZATION. ISO 214:1976: Documentation Abstracts for publications and documentation, 1976.

KOBASHI, Nair Yumiko. Elaboração de informações documentárias: em busca de uma metodologia. 1994. 195 f. Tese (Doutorado) - Curso de Ciência da Informação, Escola de Comunicações e Artes, Universidade de São Paulo, São Paulo, 1994.

KOBASHI, Nair Yumiko. Análise documentária: metodologias para indexação e resumo. [S. l: s. n.], 1995.

LANCASTER, Frederick Wilfrid. Indexação e resumos: teoria e prática. 2. ed. Brasília: Briquet de Lemos, 2004. 
LARA, Marilda Lopez Ginez de. Conceitos de organização e representação do conhecimento na ótica das reflexões do Grupo Temma. Informação \& Informação, Londrina, v. 16, n. 3, p. 92 - 121, 2011. Disponível em:

http://www.uel.br/revistas/uel/index.php/informacao/article/view/10391/9285.

NATIONAL INFORMATION STANDARDS ORGANIZATION. Guidelines for abstracts. Bethesda, MD: NISO, 1997. (ANSI/NISO Z39.14-1997 (R2015). Disponível em: https://groups.niso.org/apps/group_public/download.php/14601/Z39-14-1997_r2015.pdf. Acesso em: 02 nov. 2019.

OLIVEIRA, Laís Pereira. Análise das publicações na área de organização e tratamento da informação à luz dos resumos. Revista ACB: Biblioteconomia em Santa Catarina, Florianópolis, v. 23, n. 2, p. 245-266, abr./jul. 2018. Disponível em: https://revista.acbsc.org.br/racb/article/view/1423. Acesso em: 10 nov. 2019.

SOLLACI, Luciana Balduino; PEREIRA, Mauricio Gomes. The introduction, methods, results and discussion (IMRAD) structure: a fifty-year survey. Journal of the Medical Library Association, Chicago, v. 92, n. 3, p. 364-367, 2004. Disponível em: https://www.ncbi.nlm.nih.gov/pmc/articles/PMC442179/. Acesso em: 02 nov. 2019.

VOLPATO, Gilson Luiz. Guia prático para redação científica: publique em revistas internacionais. Botucatu: Best Writing, 2015.

VOLPATO, Gilson Luiz. Dicas para redação científica. Botucatu: Best Writing, 2016. 